\title{
IUFOST2006/413 \\ Construction and validation of a psychometric scale to measure con- sumers' fears of novel food technologies
}

\author{
G. Evans and D. Cox \\ Commonwealth Scientific and Industrial Research Organisation, PO Box 10041, SA 5000 Adelaide, Australia \\ david.cox@csiro.au
}

Consumers' perceived risks associated with novel food technologies have been recently documented. Ability to identify segments of populations that have greater or lesser neophobia in this respect so as to be able to characterise early adopters of innovative products would be useful. An established Food Neophobia Scale (FNS, Pliner \& Hobden, 1992) has proven to be more suitable for assessing reactions to ethnic foods (and sensation seeking) but less suitable for assessing receptivity to foods produced by novel technologies. Therefore there is a need to develop a new psychometric tool that taps into Novel Food Technology Neophobia (NFTN). In a three stage validation exercise, 81 statements (items) were reduced to 31 ( $\mathrm{n}=190$ ) by factor analysis; subsequently the 31 items were reduced to $14(\mathrm{n}=459)$.

The new scale was then re-tested $(n=130)$ for face validity and tested for criterion validity using the willingness to consume foods produced by a range of novel food technologies scale as the criterion measure of behavioural intention. Subsequently, convergent validity between the NFTN and general neophobia; FNS (Pliner \& Hobden, 1992); Trust in Science (Bak, 2001) and a Food Involvement Scale (Bell \& Marshall, 2003) was assessed.

Preliminary results Face validity. A principal component analysis with the 14 items revealed a KMO = 0.705 and 5 factors explaining $62.1 \%$ of the variance. Criterion validity. NFTN was significantly negatively associated willingness to try foods produced by novel technologies $(\mathrm{r}=-0.45, \mathrm{p}<0.001)$. Mean scores for willingness to try 7 of 8 foods produced by novel technologies were significantly higher $(\mathrm{p}<0.05-0.001)$ for the lowest scoring NFTN scale tertile in contrast the highest scoring tertile. Convergent validity. NFTN was significantly negatively associated (Pearson's correlations, $r$ ) with trust in science $(r=-0.44, p<0.001)$ but not with food involvement $(\mathrm{r}=-0.17, \mathrm{p}=0.058)$ and positively associated with general neophobia $(\mathrm{r}=0.26$, $\mathrm{p}=0.003)$ and the NFS $(\mathrm{r}=0.26, \mathrm{p}=0.002)$.

Pliner, P., and Hobden, K. (1992) "Development of a scale to measure the trait of food neophobia in humans". Appetite. 19, 105-120. Bak, H.(2001). Education and public attitudes toward science: Implications for the "deficit model" of education and support for science and technology, Social Sciences Quarterly, 82(4), 779793. Bell, R., \& Marshall, D.W. (2003). The construct of food involvement in behavioral research: scale development and validation, Appetite, 40(3), 235-244. 